\title{
What Governs Your Emotions- Let the Hormones Talk: A Questionnaire Study!!!
}

\section{Pallab Roy ${ }^{1}$, Shailaja Kushwaha ${ }^{2}$, Shivangi Pandey ${ }^{2}$ and Gaurav ${ }^{3 *}$}

${ }^{1}$ Private Practitioner, Sri Krishna Seva Shrama Hospital, Bangalore, Karnataka, India

${ }^{2}$ House Surgeons, NSVK Sri Venkateshwara Dental College and Hospital, Bangalore, Karnataka, India

${ }^{3}$ Consultant Oral Physician and Maxillofacial Radiologist, Assistant Professor, Department of Oral Medicine and Maxillofacial Radiology, Bangalore Institute of Dental Sciences and Hospital and Postgraduate Research Centre, Bangalore, Karnataka, India

*Corresponding Author: Gaurav, Consultant Oral Physician and Maxillofacial Radiologist, Assistant Professor, Department of Oral Medicine and Maxillofacial Radiology, Bangalore Institute of Dental Sciences and Hospital and Postgraduate Research Centre, Bangalore, Karnataka, India.
Received: May 13, 2021

Published: May 24, 2021

(C) All rights are reserved by Gaurav., et al.

\begin{abstract}
Background: Emotions are an integral part of life which affect our daily activities. These are strong feelings derived from circumstances, stress, mood, or relationship with others. Stress, according to Hans Seyle, is defined as non-specific response of the body to any demand for change. Some people use stress to refer to an overbearing or some other unpleasant situation they were subjected to. It can be classified as a type of emotion, as it can affect the decisions made by an individual. Hormones such as Dopamine, Endorphins, Serotonin and Oxytocin predominantly affect human emotions and are therefore directly related to emotions This concept also governs the fundamentals of an important group of disorders called Psychosomatic Disorders affecting a wide range of population. A better understanding of this relationship can therefore definitely be used to lead a more fulfilling life.

Aim: To assess the awareness amongst faculty of our institution on the relationship between emotions, stress and hormones and their response towards it.

Methodology: This questionnaire study is based on the modified version of the actual concepts designed by Karim Elsheikh (Founder of Inner Conqueror) who probably for the first time derived a directly proportional relationship between our emotions and the role of few hormones in governing them. The questionnaire was filled by the faculty of all the department of our institution and then the data subjected to statistical analysis.

Result and Conclusion: After analysing and interpreting the study, we can conclude that Psychosomatic disorders are untreated in majority of the cases because of unawareness of their pathophysiologies and insufficiency of expertise in clinicians to diagnose them. Keywords: Questionnaire; Emotions; Hormones; Serotonin; Dopamine
\end{abstract}

\section{Introduction}

Emotion is defined as a strong feeling deriving from one's circumstances, mood or relationships with others [1].

Hormones are defined as a regulatory substance produced in an organism and transported in tissue fluids such as blood or sap to stimulate specific cells or tissues into action $[1,2]$.
Types of hormones include [3]:

- $\quad$ Steroid hormones

- Peptide hormones

- Amine hormones.

The relation between stress and hormones and lifestyle can be understood in brief here. 


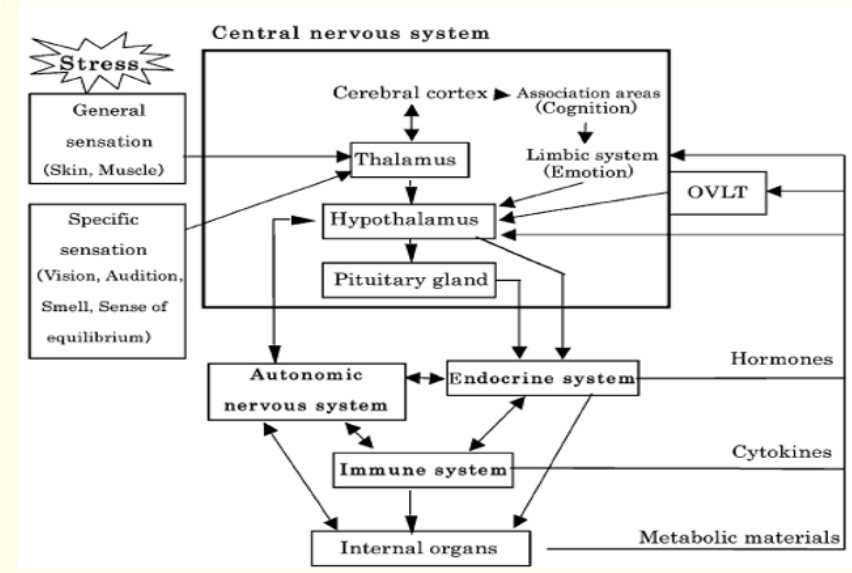

Figure 1

When a person is stressed there is release of excess cortisol in the body. This in turns weakens the lymphoproliferative response, because of which signals in the form of hormonal proteins and cytokines do not reach the brain and neuroendocrine system $[4,5]$. As an effect of which the equilibrium is disturbed causing declined development, declined memory and declined wound healing. All this leads to an altered and depressed life [6].

\section{Aim of the Study}

To assess the awareness amongst various faculty of our institution on the relationship between emotions, stress and hormones and their response towards it.

\section{Materials and Methods}

This Questionnaire based study is based on the modified version of the actual concepts designed by Karim Elsheikh (Founder of Inner Conqueror) who probably for the first time derived a directly proportional relationship between our emotions and the role of few hormones in governing them. This Questionnaire consisted of 53 questions in total out of which 10 most important questions making significant emphasis on the result have been discussed. The questionnaire was filled by all the faculty of our institution and then the data subjected to statistical analysis.

\section{Questionnaire}

1) I am poor, sick; I have mastered almost nothing that I wanted to master. Why am I still happy and satisfied?

a) The functioning of the above mentioned hormones is in conjunction with each other b) It is governed by the balance between psyche and soma

c) Psychosomatic disorders are not a part of this concept

d) Not sure

2) Happiness is related to which of the following chemicals?
a) Dopamine and endorphins
b) Serotonin
c) Oxytocin
d) All of the above

3) To differentiate between true and materialistic happiness, secretion of chemicals from the brain is the governing factor.
a) Yes
b) Is that so?
c) Unaware
d) Could be

4) I am rich, fit, and I have mastered almost everything I wanted to master. Why am I not still happy and still not satisfied? Is it governed by hormones?
a) Agree
b) Disagree
c) Not sure
d) Maybe/ Never knew this concept

5) Human happiness is incomplete without all 4 chemicals constantly being released in the brain. Is it applicable scientifically?
a) Yes
b) No
c) Maybe
d) Unaware

6) Is achieving satisfaction level in all walks of life dependent on the release of the 4 hormones spoken above?
a) Yes, agree
b) No, don't agree
c) Not aware
d) Maybe

7) Axis II disorders of orofacial pain are governed by psyche and soma.
a) Yes
b) Partially
c) They are the basics of psychosomatic disorders
d) Not aware 
8) For achievement of goals, which of the following chemicals should be secreted from the brain?
a) Dopamine
b) Serotonin
c) Oxytocin
d) Endorphins

9) Handling relationships and living a contented life reduces stress and, thereby, the chances of psychosomatic disorders.
a) Oxytocin is the governing factor
b) There is no role between hormones and psychosomatic disorders
c) The association is not established
d) Maybe

10) Why am I not OK with everything? Could I be suffering from one of the mood/anxiety disorders (Axis II disorders of orofacial pain)?
a) Yes, most likely
b) Unaware
c) No
d) Never thought about it.

\section{Result}

After the questionnaire was filled and the data was subjected to statistical analysis, we obtained following significant tables and graphs from the 53 questions which determine the aim of the study.

Q1: I am poor, sick; I have mastered almost nothing that I wanted to master. Why am I still happy and satisfied?

\begin{tabular}{|c|c|c|}
\hline $\begin{array}{c}\text { The functioning of above mentioned } \\
\text { hormones is in conjunction with each other }\end{array}$ & Frequency & Percent \\
\hline $\begin{array}{c}\text { It is governed by the balance between Psyche } \\
\text { and Soma }\end{array}$ & 14 & 22.5 \\
\hline $\begin{array}{c}\text { Psychosomatic disorders are not a part of } \\
\text { this concept }\end{array}$ & 9 & 22.5 \\
\hline Not sure & 8 & 20.0 \\
\hline Total & 40 & 100.0 \\
\hline
\end{tabular}

Table 1: As it is evident from the above table,35\% of the professionals believe in individual happiness depending upon the balance between Psyche and Soma and not solely on achievements.

$20 \%$ of the professionals however are not sure about this.
Q2: Happiness is related to which of the following chemicals?

\begin{tabular}{|c|c|c|}
\hline & Frequency & Percent \\
\hline Dopamine and endorphins & 8 & 20.0 \\
\hline Serotonin & 4 & 10.0 \\
\hline Oxytocin & 4 & 10.0 \\
\hline All of the above & 24 & 60.0 \\
\hline Total & 40 & 100.0 \\
\hline
\end{tabular}

Table 2: Shows that $60 \%$ of the professionals believe that happiness is related to all the 4 chemicals that is dopamine, serotonin, oxytocin and endorphins, $20 \%$ of them believe that it depends only on dopamine and endorphins, $10 \%$ of them believe that happiness depends on Serotonin alone and the rest $10 \%$ of them believe that it is oxytocin dependent.

Q3: To differentiate between true and materialistic happiness, secretion of chemicals from the brain is the governing factor?

\begin{tabular}{|c|c|c|}
\hline & Frequency & Percent \\
\hline Yes & 13 & 32.5 \\
\hline Is that so? & 11 & 27.5 \\
\hline Unaware & 4 & 10.0 \\
\hline Could be & 12 & 30.0 \\
\hline Total & 40 & 100.0 \\
\hline
\end{tabular}

Table 3: As shown in the table above to differentiate between true and materialistic happiness, $32.5 \%$ of the professionals are confirmed that secretion of chemicals from the brain is definitely the governing factor, $30 \%$ of them believe that maybe it is possible that chemicals from brain are the governing factor, $22.5 \%$ of them are not sure and $10 \%$ of them are not aware of it.

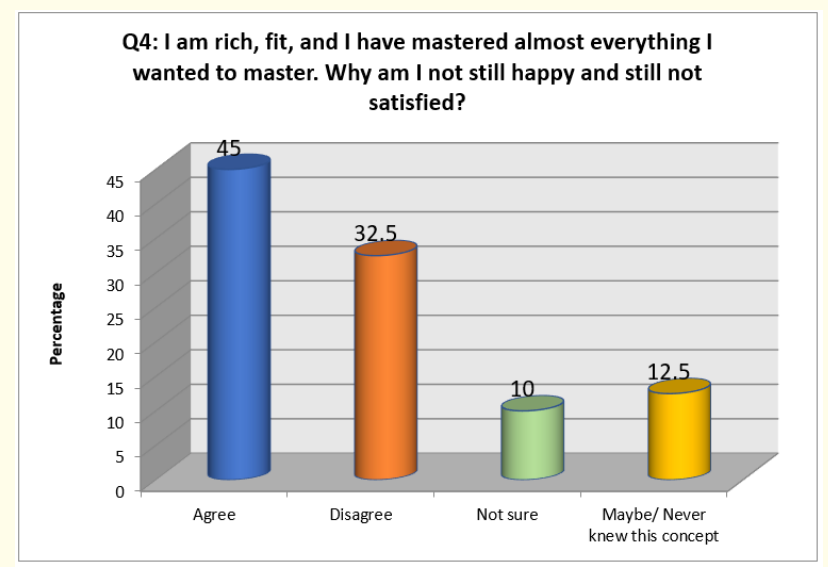

Graph 1: Shows, that $10 \%$ of the people are not sure whether happiness is governed by hormones and $12.5 \%$ of practitioners did not know the concept. 


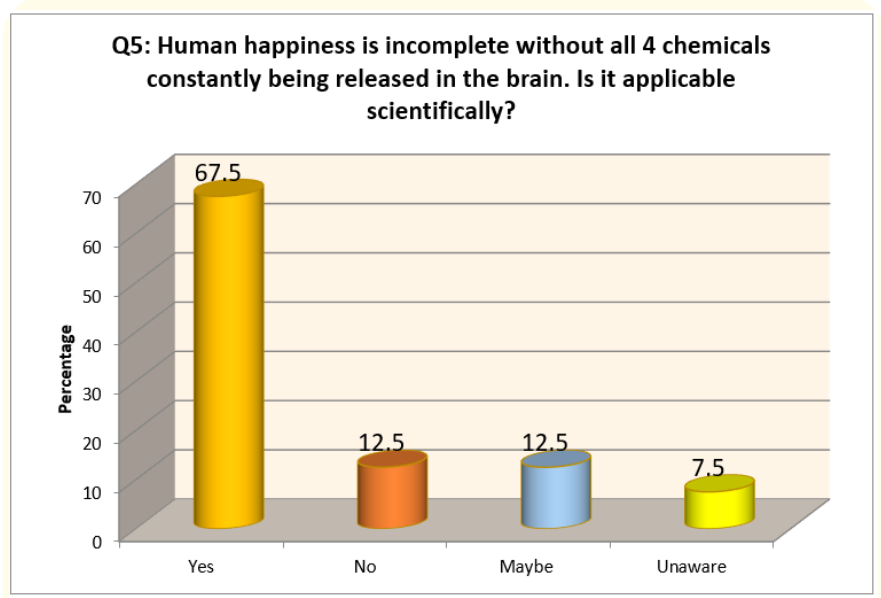

Graph 2: As seen here most of the practitioners gave a satisfactory response showing $67.5 \%$ answering in affirmation whereas $50 \%$ of them being unaware about the relationship of released chemicals(hormones) and human happiness.

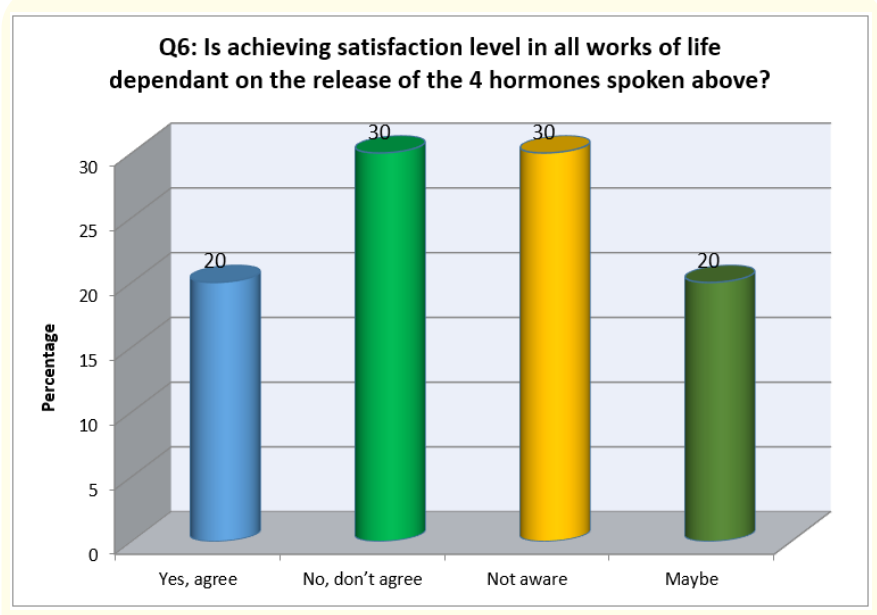

Graph 3: Shows that only $20 \%$ of the professionals agreed on the fact that satisfaction level in life is dependent on the release of 4 hormones, rest of them are either not aware, not sure or do not agree with it.

\section{Discussion}

A psychosomatic disorder is a disease which involves both mind and body. Sometimes mental and emotional factors may act as risk factor that could influence the initiation and progression of oromucosal disorders. The term Psychosomatic is derived from Greek word "Psyche" (mind) and "Soma" (body) [7].

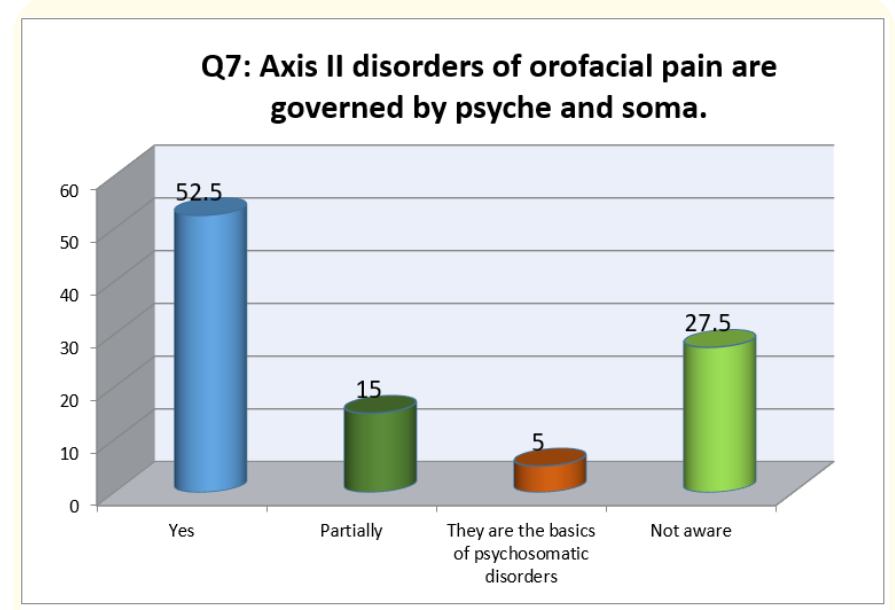

Graph 4: Shows variation in the views of professionals. As it shows $52.5 \%$ of them believing in Axis II disorders of Orofacial pains are governed by Psyche and Soma. 27.5\% of them are unaware about any such relations between Axis II disorders of Orofacial pains and Psyche and Soma. A very few, precisely 5\% of them believe that

Psyche and Soma are the basics of Psychosomatic disorders.

Q8: For achievement of goals, which of the following chemicals should be secreted from the brain?

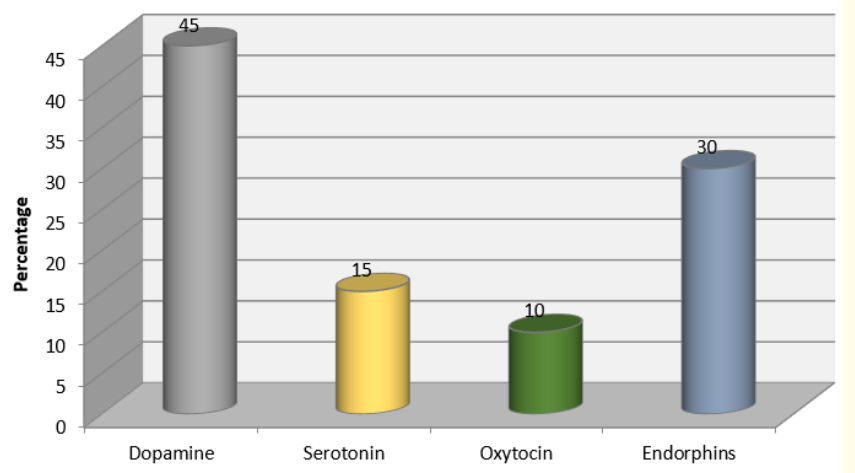

Graph 5: As the analysis shows there is a marked difference in the views of professionals, $45 \%$ of them believe that Dopamine is the chemical which should be secreted from brain for the achievement of goals, $30 \%$ of them consider the chemical to be Endorphins, $15 \%$ as Serotonin and $10 \%$ as Oxytocin.

The hormones and chemicals governing psyche and soma are:

1. Dopamine

2. Serotonin

3. Oxytocin

4. Endorphins 
Q9: Handling relationships and leaving a contented life reduces stress and, thereby, the chances of psychosomatic disorders.

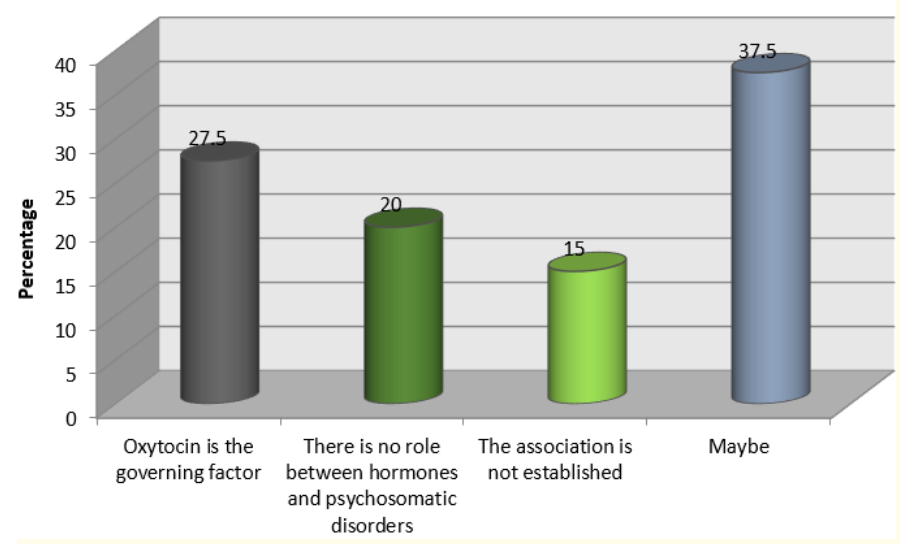

Graph 6: As the given graph clearly portrays that $20 \%$ of the professionals consider there is no role between hormones and Psychosomatic disorders, $15 \%$ of believe that the association between hormones and disorders are still not established. About $27.5 \%$ of them consider that Oxytocin is the major governing factor.

\section{0: Why am I not OK with everything? Could I be suffering from one of the mood/anxiety disorders (Axis II disorders of orofacial pain)?}

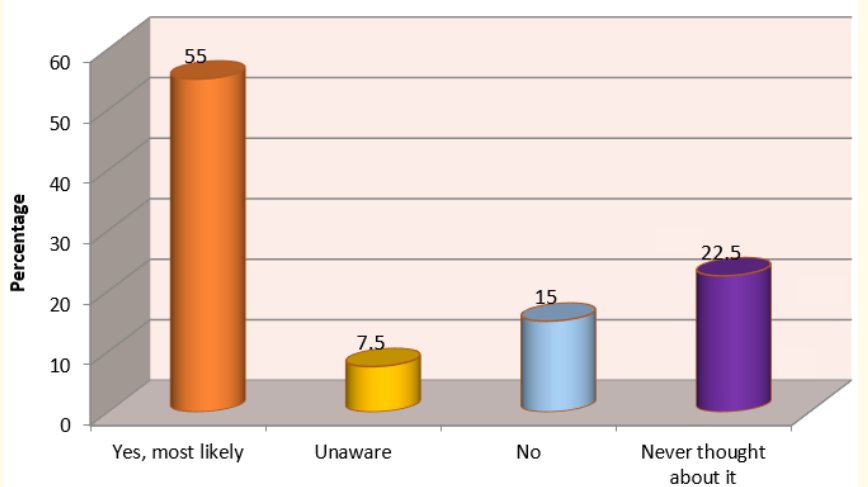

Graph 7: As it is clear from the above graph that more than half of the professionals gave positive opinion showing $55 \%$ of them most likely believing that being not okay with things in life should be considered as suffering from anxiety/mood disorders. About $15 \%$ of them believe that there is no such relation between not being okay and anxiety disorders whereas others are either unaware or have never thought about it.

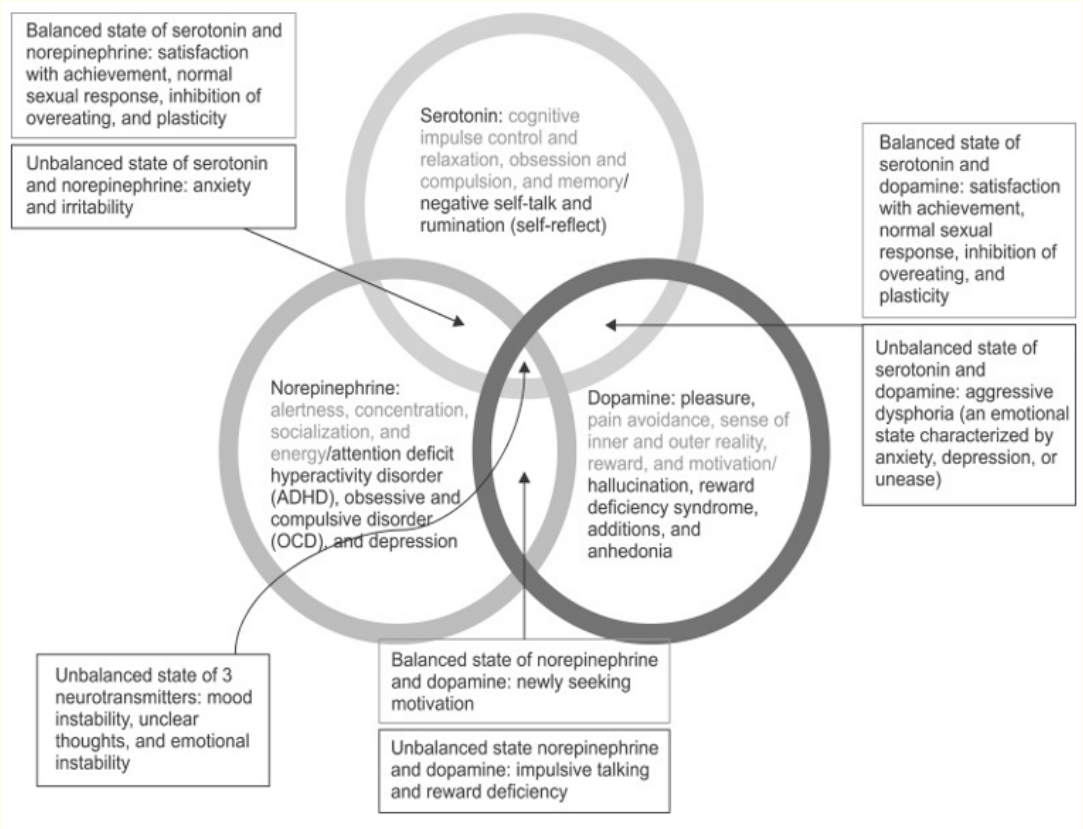

Figure 2 
The role of chemicals in oral medicine is explained by examples below:

- When a person is stressed there are release of Epinephrine, Norepinephrine, Serotonin, Dopamine causing excitation of nerve cells in muscles. This causes increased muscle tension, reduced local blood flow, reduced oxygen and ATP reserves [8]. In response, there are altered calcium pump actions causing Myofascial pain.

- If a person is stressed, the Beta-adrenergic receptors get activated causing release of exogenous Noradrenaline. This lowers the density of nerve fibres and there is axonal degeneration. As a result, there is Burning Mouth Syndrome and Xerostomia since the gustatory information is modulated $[9,10]$.

Classification of oral psychosomatic disorders \{Bailoor and Nagesh (2001)\}:

1. Pain related disorders:

- Myofascial pain

- Atypical fascial pain

2. Disorders related to altered oral sensation:

- Burning mouth syndrome

- Idiopathic xerostomia

3. Miscellaneous:

- Oral lichen planus

- Recurrent apthous ulcers

- Psoriasis

- Erythema multiforme

- Cancerophobia

- ANUG

- Anorexia nervosa

- Bruxism.

\section{Conclusion}

After analysing the above graphs and tables we can conclude that most of the Psychosomatic disorders remain untreated because of the unawareness of their pathophysiologies as well as inefficiency of clinicians to diagnose them effectively based on presenting signs and symptoms. As it is said that eyes see what the mind knows, therefore knowledge of pathophysiology lays the foundation of an accurate diagnosis and an effective treatment plan. Hence with accurate knowledge of pathophysiology and signs and symptoms of such disorders it can be possible to address them in a right way

\section{Bibliography}

1. Dhimole., et al. "Psychosomatic Disorders Affecting the Mouth: A Critical Review". British Journal of Medicine and Medical Research 14.1 (2016): 1-9.

2. Thorakkal Shamim. "A Simple Working Type Classification Proposed for the Psychosomatic Disorders of the Oral Cavity". Journal of the College of Physicians and Surgeons Pakistan 22.3 (2012): 612-614.

3. Bahman Tofighi. "A Study of the Relationship Between Stress and Psychosomatic Disorders". Department of Consulting, Bushehr Branch, Islamic Azad University, Bushehr, Iran.

4. Fowkes FG., et al. "Serum cholesterol, triglycerides, and aggression in the general population". Lancet 340.8826 (1992): 995-998.

5. Muldoon MF., et al. "Lowering cholesterol concentrations and mortality a quantitative review of primary prevention trials". British Medical Journal 301.6 (1990): 309-314.

6. Chojkier M. "Inhibition of albumin synthesis in chronic diseases: molecular mechanisms". Journal of Clinical Gastroenterology 39.5 (2005): 143-146.

7. Spector P. "Individual differences in the job stress process of healthcare professionals". In Firth-Cozens J, Payne R, Stress in health professionals". Chichester: Wiley and Sons, UK (1999).

8. Firth-Cozens J and Payne R. "Stress in health professionals". Chichester: Wiley and Sons (1999).

9. Cooper CL., et al. "Job satisfaction, mental health and job stressors among General Dental Practitioners in the UK". British Dental Journal 24 (1987): 77-88.

10. Goldberg D. "General health questionnaire (GHQ-12)”. Windsor: NFER-NELSON (1992).

Volume 5 Issue 6 June 2021 (C) All rights are reserved by Gaurav., et al. 